\title{
Summary of Pilot-Scale Activities with Mercury Contaminated Sludges (U)
}

by

C. A. Cicero

Westinghouse Savannah River Company

Savannah River Site

Aiken, South Carolina 29808

N. D. Hutson

J. R. Zamecnik

M. E Smith

D. H. Miller
J. A Ritter
B. J. Hardy
C. M. Jantzen

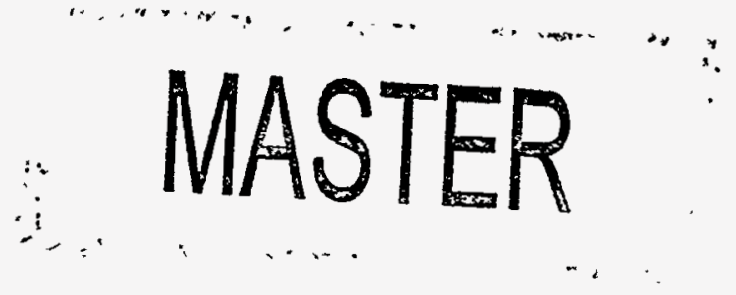

This paper was prepared in connection with work done under the above contract number with the $U$. $S$. Department of Energy. By acceptance of this paper, the publisher and/or recipient acknowledges the U.S. Government's right to retain a nonexclusive, royalty-free license in and to any copyright covering this paper, along with the right to reproduce and to authorize others to reproduce all or part of the copyrighted paper. 


\section{DISCLAIMER}

Portions of this document may be illegible in electronic image products. Images are produced from the best available original document. 


\section{DISCLAIMER}

This report was prepared as an account of work sponsored by an agency of the United States Government. Neither the United States Government nor any agency thereof, nor any of their employees, makes any warranty, express or implied, or assumes any legal liability or -responsibility for the accuracy, completeness, or usefilness of any information, apparatus, product, or process disclosed, or represents that its use would not infinge privately owned rights. Reference herein to any specific commercial product, process, or service by trade name, trademark, manufacturer, or otherwise does not necessarily constitute or imply its endorsement, recommendation, or favoring by the United States Government or any agency thereof. The views and opinions of authors expressed herein do not necessarily state or reflect those of the United States Government or any agency thereof.

This report has been reproduced directly from the best available copy.

Available to DOE and DOE contractors from the Office of Scientific and Technical Information, P.O. Box 62, Oak Ridge, TN 37831; prices available from (615) 57.6-8401.

Available to the public from the National Technical-Information Service, U.S. Department of Commerce, 5285 Port Royal Road, Springfield, VA 22161. 


\title{
Q. Westinghouse Savannah River Company Savannah River Technology Center
}

WSRC-TR-95-0404
Revision 0

Keywords: sludge, vitrification, glass, mercury

September 30, 1995

\section{SUMMARY OF PILOT-SCATE ACTIVITIES WITH MERCURY CONTAMINATED SIUDGES :}

\author{
Compiled by: Connie A. Cicero \\ Contributing Authors: Nick D. Hudson, Jack R. Zamecnik, \\ Mike E. Smith, Don H. Miller, Jim A. Ritter, \\ Bruce J. Hardy, and Carol M. Jantzen
}

\section{SUMMARY}

Technologies for treatment of low level mixed wastes (ILMW) are currently being investigated by the Mixed Waste Focus Area (MWFA) of the Department of Energy (DOE). The Savannah River Technology Center (SRTC) has been chartered by the MWEA to study vitrification treatment of the wastes through an Office of Technology Development (OTD) Technical Task PIan (TTP). SRTC's efforts have included crucible-scale studies and pilot-scale testing on simulated LLMW sludges, resins, soils, and other solid wastes. Results from the crucible-scale studies have been used as the basis for the pilot-scale demonstrations.

One of the streams to be investigated in fiscal year (FY) 1995 by SRTC was a mercury waste. In FY 1995, SRTC performed crucible-scale studies with mercury contaminated soil. This waste stream was selected because of the large number of DOE sites that have an inventory of contaminated or hazardous soil. More importantly, it was readily available for treatment. Pilot-scale studies were to be completed in FY 1995, but could not be completed due to a reduction in funding. Since the main driver for focusing on a mercury waste stream was to determine how the mercury could be treated, a compilation of pilot-scale tests with mercury sludges performed under the guidance of SRTC is provided in this report. 
The studies summarized in this report include several pilot-scale vitrification demonstrations with simulated radioactive sludges that contained mercury. The pilot-scale studies were performed at the SRTC in the Integrated Defense Waste Processing Facility (DWPF) Melter System (IDMS). The studies involved complete glass and offgas product characterization.

Future pilot-scale studies with mercury streams will likely be performed with mercury contaminated soils, sediments, or sludges because of the need to dispose of this technically challenging waste stream. These pilot-scale studies are likely to focus on new technologies for capturing and converting the mercury to a stable form, since technologies have already been developed for treating most of the residual waste matrices.

\section{BACKGROUND}

Radioactive and mixed waste sludges containing mercury have resulted from the use of mercuric nitrate as a catalyst during. nitric acid dissolution of spent fuel rods at the Savannah River Site (SRS). Treatment methods for disposing of most of these wastes are still being determined, but the high level waste (HLW) mercury containing sludges will be disposed of in the DWPF using vitrification. Since mercury tends to decompose at temperatures much less than the melt temperature of most glasses developed for radioactive wastes, most of the mercury must be removed prior to vitrification. The decomposition of mercury presents two problems, which include environmental release of a toxic substance and release to offgas systems incapable of handling the mercury compounds emitted. When mercury exits in the offgas, it can be present as a complex mixture of halides, oxides, and metals. This mercury mixture would be hard to process, recover, and purify and would also present a corrosion problem to the offgas system. ${ }^{1}$ Therefore, mercury should be removed before the vitrification portion of the process.

\section{IDMS DEMONSTRATIONS}

When vitrifying sludge, the IDMS removes the mercury in the sludge via reduction to mercury metal using formic acid and steam stripping in the Slurry Receipt and Adjustment Tank (SRAT). The mercury is then collected and washed in the Mercury Wastewater Wash Tank (MWWT) before being sent to the Mercury Purification Cell. Any mercury that remains in the melter feed is captured in the offgas system.

Several runs with simulated sludge containing mercury were performed in the IDMS to determine the effects of mercury on the feed preparation process, off-gas chemistry, melting behavior, and glass durability. In all runs, the mercury containing sludge was mixed with the proper additives to make homogeneous glass. The trial names were HG1, HG2, HG3, HM4, PX3, PX4, and PX5. Three of the runs were marginally the same composition (HG1, HG2, and HG3), while the other four were slightly different feed compositions. The specific goal of the three runs with marginally the same composition was to determine the behavior 
of mercury in the whole system. Over 15,000 pounds of glass were poured during these three mercury runs.

For the four other runs, nitric acid was used to neutralize the sludge components (hydroxides and carbonates) as opposed to the formic acid used in the first three runs. Sufficient formic acid in the rest of the melter feed was available to complete the necessary reduction/ oxidation reactions for these four trials. Once again, these reactions were necessary to allow mercury to reduce to its metal state, so it could be steam stripped. 1

\section{MELTER FEED PREPARATION}

The preparation of feed for the runs in the IDMS represented the first large-scale demonstration of mercury removal and recovery at the SRS. The system consists of a SRAT/SIurry Mix Evaporator (SME), a SRAT/SME condenser, a MWWT, and a Waste Water Pump Tank (WWPT). ${ }^{2}$ The processing steps for treating the mercury included:

1) formic acid addition to control glass redox, improve feed rheology, and reduce mercury to the metallic form,

2) refluxing to remove mercury by steam stripping, and then concentrating by boiling,

3) Precipitate Hydrolysis Aqueous ( $\mathrm{PHA}$ ) addition, concentration by boiling and, if necessary, further refluxing to remove mercury.

In each of the designated mercury runs (HG1, HG2, and HG3), the sludge solids to be used were transferred from the Sludge Receipt Tank (SRT) to the IDMS SRAT/SME in preparation for feeding to the melter. The mercury additions were performed separately. In order to convert mercury to the desired form, mercurous nitrate was added to nitric acid and heated to about $60^{\circ} \mathrm{C}$ to convert $\mathrm{Hg}^{1+}$ to $\mathrm{Hg}^{2+}$ and then the mercuric nitrate solution was added to the sludge in the SRAT/SME. ${ }^{2}$ Upon addition to the sludge, the mercuric nitrate reacted to form mercuric oxide, which is the anticipated form in SRS radioactive waste.

The melter feed streams for runs HG1, HG2, and HG3 contained 28\%, 28\%, and $26.7 \%$ sludge oxides, respectively. ${ }^{1}$ Analyses of the feed from the three runs is given in Table 1 . As can be seen from the mercury results provided in the table, detection of the mercury in the feed stream was very difficult due to analytical technique. The theoretical elemental mercury concentrations were 1.22 wt: for HG1, 1.19 wt: for HG2, and 1.22 wt: for HG3. For the four additional sludge runs, the sludge oxide loadings were equivalent to those in the mercury runs, and the initial concentration of mercury in the sludge was targeted at 3.2 wt\% on a dry basis. ${ }^{1}$ 


$\begin{array}{crcc}\text { Table } 1-\text { Mercury } & \text { Run Feed } & \text { Compositions } & {\text { (Wt })^{2}}^{2} \\ \text { Qxide } & \text { HGI } & \text { HG2 } & \text { HG3 } \\ \mathrm{Al} & 2.101 & 1.929 & 1.829 \\ \mathrm{~B} & 1.882 & 1.383 & 1.446 \\ \mathrm{Ba} & 0.059 & 0.058 & 0.053 \\ \mathrm{Ca} & 0.619 & 0.609 & 0.580 \\ \mathrm{Cr} & 0.072 & 0.060 & 0.054 \\ \mathrm{Cs} & 0.020 & 0.053 & 0.000 \\ \mathrm{Cu} & 0.155 & 0.087 & 0.106 \\ \mathrm{Fe} & 7.193 & 6.832 & 6.491 \\ \mathrm{Hg} & 0.000 & 0.000 & 0.034 \\ \mathrm{~K} & 1.466 & 0.920 & 1.228 \\ \mathrm{Ii} & 1.728 & 1.460 & 1.431 \\ \mathrm{Mg} & 0.728 & 0.581 & 0.583 \\ \mathrm{Mn} & 1.364 & 1.229 & 1.144 \\ \mathrm{Na} & 5.770 & 6.331 & 4.152 \\ \mathrm{Ni} & 0.395 & 0.404 & 0.376 \\ \mathrm{P} & 0.016 & 0.010 & 0.010 \\ \mathrm{~Pb} & 0.141 & 0.094 & 0.057 \\ \mathrm{Si} & 19.948 & 18.339 & 15.328 \\ \mathrm{Sr} & 0.022 & 0.021 & 0.018 \\ \mathrm{Ti} & 0.130 & 0.107 & 0.119 \\ \mathrm{Zn} & 0.277 & 0.153 & 0.161 \\ \mathrm{Zr} & 0.060 & 0.057 & 0.020 \\ & & & \end{array}$

The mercury that was collected in the MWWT was recovered and washed. This mercury was accompanied both by heavy organic material and entrained solids. When the mercury washing was performed on a laboratory scale, problems were encountered because of the presence of the organic material and the entrained solids. The heavy organics and solids were difficult to separate from the mercury and could possibly require several "wash cycles" to remove on a larger scale. It was determined that this removal would only be effective if there was an evenly distributed vigorous air sparge in the mercury pool. ${ }^{2}$

\section{OFFGAS SYSTEM OPERATIONS}

In order to contain all of the mercury and organic vapors in the Feed Preparation System, all of the vessels were maintained under a vacuum using the Process Vessel Vent System (PVVS). The PVVS serves every vessel containing mercury and organics in the IDMS except the melter and the Offgas Condensate Tank (OGCT).

Offgas generated from the melter consisted of steam, non-condensable gases from sludge decomposition, air from inleakage and purges, mercury vapor, and particulate matter from entrainment and volatilization. Therefore, the melter offgas system had to maintain a negative pressure in the melter plenum, provide adequate combustion in the melter vapor space, ensure ventilation and treatment of the reaction gases and steams released from the melter, and provide melter pour spout vacuum to initiate and control glass pouring. 
The IDMS melter was purged with air during operation. Offgas exiting the melter passed through a film cooler designed to minimize particulate build up in the offgas line. This film cooler also reduced the offgas from $450-725^{\circ} \mathrm{C}$ to less than $350^{\circ} \mathrm{C}$. After passing through the film cooler, the gas was then scrubbed in the quencher. The quencher was an ejector-venturi scrubber, which reduced the gas temperature below the dew point, disengaged most of the water vapor from the non-condensables, scrubbed entrained glass, and allowed semi-volatile particles (salts) to coalesce. Offgas condensate was used as the motive fluid for the quencher. Any offgas and condensate that left the quencher entered the OGCT where the Iiquid and vapor disengaged. 3

The offgas from the OGCT was passed through two Steam Atomized Scrubbers (SAS), which removed particulates by combining water with the offgas in a region of turbulent mixing. The droplets of water formed were separated from the vapor in a cyclone separator. The condensate and condensate steam were then returned to the OGCT. The offgas leaving the SAS was passed though a heat exchanger that was designed to separate the condensables from the offgas and remove virtually all of any elemental mercury present. The separated condensables were then returned to the OGCT. Any suspended liquid droplets from the non-condensable gases were removed with an atomized water spray in the High Efficiency Mist Eliminator (HEME).3

After passing through the HEME, the offgas was heated $10^{\circ} \mathrm{C}$ above its dew point to prevent condensation in the High Efficiency Particulate Airfilters (HEPA). The offgas passed through two HEPA filters in parallel, which served as the final treatment step before release to the environment. 3

The WWPT collecteds the condensate from the MWWT, Formic Acid Vent Condenser (FAVC), OGCT, PVVS Stack and Offgas Stack for treatment on two ion exchange columns. The condensate in the tank was $\mathrm{pH}$ adjusted to approximately 12 to precipitate most of the solids so they could be pumped through an ultrafilter unit for removal of the particulates and colloids.2 The filter water was then passed through two ion exchange columns to remove soluble mercury.

Duolite ${ }^{\mathrm{TM}} \mathrm{GT}-73$ ion exchange resin was used to remove mercury from the waste condensate and sump water generated during the process

demonstrations. The waste was treated on two $0.40 \mathrm{~m}^{3}$ columns at a flow rate of $0.1 \mathrm{~m}^{3} / \mathrm{min}$. This resin was a polystyrene/divinylbenzene resin with thiol $(\mathrm{S}-\mathrm{H})$ functional groups. On a laboratory scale, it was effective in sorption of $\mathrm{Hg}^{2+}, \mathrm{Hg}_{2}{ }^{2+}$, and $\mathrm{Hg}^{0}$. Leach tests of the resin indicated that it did not lose any $\mathrm{Hg}$ on leaching, and, therefore, was not a secondary waste. The overall capacity in column operation for this waste is about 145 grams Hg/liter of resin. For the IDMS, it has been found to reduce the $\mathrm{Hg}$ content to below the permitted level of 10 $\mu \mathrm{g} / \mathrm{I}$ for subsequent processing and effluent has been $<5 \mu \mathrm{g} / \mathrm{I} \mathrm{Hg} .4$

Observations for each of the runs pertaining to the offgas system are discussed below. 
HGI

After the feed preparation step, no metallic mercury had accumulated in the mercury sump of the MWWT. Since this was not expected, the condensate line was inspected from the SRAT condenser to the MWWT. The inspection found a large amount ( $>10$ pounds) of elemental mercury trapped in the pipe. The piping connecting these two pieces of equipment was nearly horizontal in some locations, which did not provide enough gravitational flow for the mercury vapors. The mercury was found trapped in the thermowell and at the entrance to the condensate flow measurement device where decreased diameter piping was used. These mercury accumulations caused pressure control problems in the vessel vent system.

HG2

Due to the problems with mercury being trapped in the piping in HG1, slope was added to the line from the SRAT condenser to the MWWT and the piping was replaced with tubing that did not have low points and mercury traps. The modification did not help significantly in allowing the mercury to be collected in the MWWT. Upon inspection of the piping, elemental mercury was found in the line around the flow measurement device again.

During this run, the PVVS offgas entering and leaving the FAVC was sampled for mercury using a modified EPA Method 5 sampling train. The impingers used contained $2 \mathrm{M}$ nitric acid instead of water because nitric acid was believed to capture mercury better. However, hardly any mercury was detected in the solutions.

Also during this run, the feed system was briefly interlocked due to FAVC vapor exit temperatures momentarily exceeding $20^{\circ} \mathrm{C}$. Condensate samples taken during the reflux phase of the operation had small mercury beads present.

$\underline{\text { HG3 }}$

On account of the continued operation difficulties with the SRAT condenser to MWWT piping, the sample tap and flow measurement device were completely removed from the line. Also, the condensate flow was directed into the MWWT at a slope. These changes allowed the mercury to be easily routed to the MWWT.

The modified EPA Method 5 sampling train was also tested during this run. This time a mixture of approximately 4 (w/v) $\frac{\circ}{0}$ potassium permanganate in approximately $10(\mathrm{w} / \mathrm{v}) \%$ sulfuric acid was used instead of nitric acid. This solution was better for capturing the mercury, but still did not provide optimum results.

OTHER RUNS

The condensate generated during SRAT/SME cycles for the other four runs contained on average $105 \mathrm{mg} / \mathrm{L} \mathrm{Hg}$, with only one run not being 
consistent. The maximum Hg concentration varied considerably from run to run. The condensate generated during the melter feeding cycle was only measured for three of the runs and contained on average $92 \mathrm{mg} / \mathrm{L}$ soluble $\mathrm{Hg}$. The maximum concentration did not vary nearly as much between these runs. 5

\section{MELTER SYSTEM}

The IDMS melter is a refractory lined, cylindrical tank which operates at glass temperatures of about $1150^{\circ} \mathrm{C}$. The melter has a 24 inch inner diameter. Vitrified material is poured through a drain spout into steel canisters at a rate of about $25 \mathrm{lb} / \mathrm{hr}$. Draining of the melter is controlled by a water driven spout jet that pulis a vacuum on the melter pour spout. The melter is equipped with Inconel resistance heaters in the vapor space to assist in vaporization of the water in the slurry feed and to combust offgases evolved from the slurry.

Before the start of the mercury demonstrations, it was believed.that insoluble $\mathrm{Hg}_{2} \mathrm{Cl}_{2}$ (calomel) might form in the offgas line if mercury was carried over into the melter. Formation of insoluble $\mathrm{Hg}_{2} \mathrm{Cl}_{2}$ in the melter offgas system was not observed. Melt rates were not impacted by the addition of $\mathrm{Hg}$ in the feed. The concentration of $\mathrm{Hg}$ in the melter feed and melter offgas system was much lower than predicted, which can be attributed to the more efficient than predicted Hg stripping in the feed preparation system. During the runs, determination of the amounts of $\mathrm{Hg}$ in the feed by analyses was difficult.

Electrical characteristics of the melter electrodes were monitored during feeding and idling during the campaign and were not affected by the operations with mercury feed. During feeding, less power is required for the lower electrodes, while more power is required for the upper electrodes due to the cold cap insulating the upper glass pool from the heat given off from the lid heaters. The total electrode power remained constant. The resistance ratio of the two sets of electrodes was also tracked during the campaign, since this gives an idea about any changes in the glass pool resistivity due to changes in temperature or composition of the glass. The upper electrodes to lower electrodes resistance ratio stayed at about $1.0-1.2$. This ratio is helpful for determining if accumulation of metals is occurring.

\section{MERCURY BAIANCE}

As mentioned earlier, mercury is added to the sludge in the form of mercuric nitrate in the SRAT/SME, where it is converted to mercuric oxide. Formic acid is used to reduce the mercuric oxide to elemental mercury in the SRAT/SME product. The mercury in the SRAT/SME is then boiled with the rest of the SRAT/SME product to strip the mercury, which is recovered in the MWWT.

Mercury balances were performed around the SRAT for each of the mercury designated runs using analytical results from samples of the SRAT/SME, the WWPT, and the MWWT. A summary of the results of each of these campaigns is given in Table 2. After the final mercury designated run, 
September 30,1995

the bottom of the Melter Feed Tank was visually examined for the presence of mercury, and none was detected.

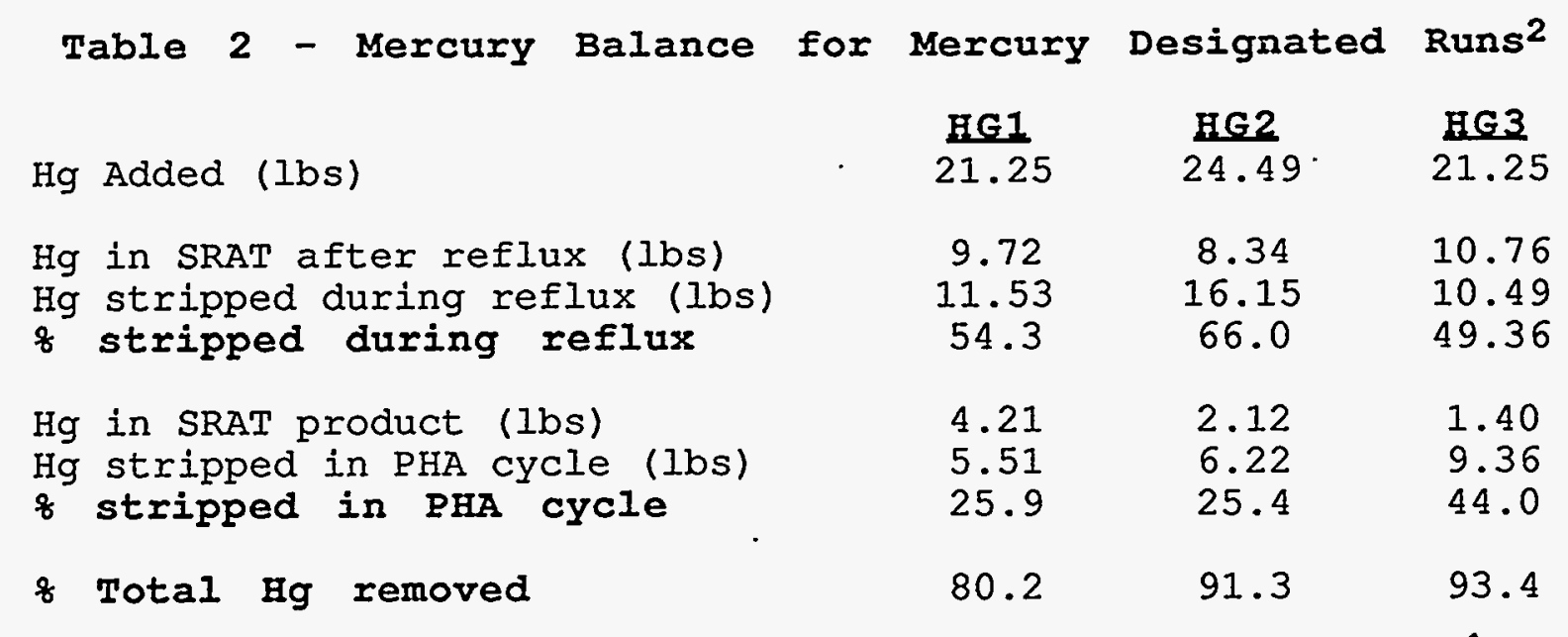

Several samples of the SRAT condensate tank were also taken during the feed preparation steps for HG1. The detected mercury varied from 5,985 to $10,465 \mathrm{ppm} .^{2}$ Both the highest and the lowest concentrations of mercury occurred during the Formic reflux period, with the highest concentration at the beginning and the lowest at the end.

A mercury balance was also performed around the entire offgas system for the three mercury designated runs. Several assumptions about the melter, mercury, and offgás behavior were assumed but will not be elaborated on here. The biggest assumptions were that all of the mercury fed to the melter exits into the offgas, that the concentration of mercury in the OGCT is the same everywhere in the tank, and that the amount of mercury accumulated on the HEME is negligible. Other errors in the balance arose due to problems with analyzing for mercury in the melter feed. Results showed that flame Atomic Absorption (AA) should not be used, and Vapor Gas Analysis (VGA) should be used instead. ${ }^{2}$

Two different types of balances were performed. The first was an unsteady-state analysis, since the concentration of mercury varies with time. ${ }^{2}$ To perform this analyses, balances were performed hourly and samples of the OGCT were taken throughout the day. For the second method, an overall material balance was performed by performing a cumulative summation of the total amounts of mercury. ${ }^{2}$ The results for both methods are shown in Table 3 .

$\begin{array}{ccc}\text { Table } 3 \text { - Melter Offgas Mercury Material Balance } \\ \text { Mercury Designated Runs } \\ \text { Instantaneous } & \text { Cumulative } \\ \text { Run } & \text { Balance } & \text { Balance } \\ \text { HG1 } & 100.0 & 91.6 \\ \text { HG2 } & 100.2 & 122.5 \\ \text { HG3 } & 99.9 & 99.9\end{array}$


The results from the melter offgas balance indicate that the amount of mercury exiting in the offgas ranged from 0.8 to $3.4 \%$. The results also showed that the mercury concentration depended somewhat on the feed concentration.

Mercury in the scrubber solutions ranged from 16 to $63000 \mu \mathrm{g} / \mathrm{I}$ for the three mercury designated runs. The OGCT condensate contained 0.84 to 1.0 parts of soluble to total mercury. Some of the entrained glass oxides in the condensate appeared to be plated with elemental mercury. The total mercury in the condensate ranged from $1.9-11.9 \mathrm{mg} / \mathrm{L}$, with virtually all of it soluble. No particulate mercury was removed in the filter papers. 3

\section{CAMPAIGN PERFORMANCE MEASURES}

The mercury Decontamination Factor (DF) across the OGCT, SAS/Offgas Condenser/Mist Eliminator combination and the HEME were determined by measuring the amount of mercury in the offgas for HG2 and HG3. The DF reported is the ratio of the amount of mercury entering the equipment to the amount leaving. Particulate samples were also taken from the offgas on $0.45 \mu \mathrm{m}$ filter paper. Analysis of the papers by $\mathrm{X}$-ray Fluorescence and electron microscopy showed no evidence of mercury.

The mercury DF's for both the OGCT and the HEME were larger than predicted. 2 The design basis for the HEME assumed that most of the mercury entering the HEME was elemental mercury vapor and that it would not be removed, but some mercury was removed. Since the HEME was wetted by a constant stream of water, the $\mathrm{HgO}$ and $\mathrm{HgCl}_{2}$ in the offgas were scrubbed by the HEME. ${ }^{3}$ The DF for the Steam Atomized Scrubber (SAS)/Offgas Condenser/Mist Eliminator was smaller than predicted.

Table 4 shows the DFs for runs HG2 and HG3.

$\begin{array}{ccc}\text { Table 4 - Mercury } & \text { Decontamination } & \text { Factors } \\ & & \\ \text { Equipment } & \text { HG2 } & \text { HG3 } \\ \text { OGCT } & 8.28 & 3.32 \\ \text { SAS/OG Cond/ME } & 4.86 & 1.60 \\ \text { HEME } & 1.84 & 5.58 \\ \text { Overall } & 74.2 & 29.7\end{array}$

The concentrations of mercury in the melter offgas system for the mercury designated campaigns are given in Table 5 . Concentrations were lower than predicted due to more efficient than predicted steam stripping efficiency.

$\begin{array}{cc}\text { Table 5 - Mercury Concentrations in the Melter offgas system } & \text { sy }^{2} \\ \text { Process stream } & \text { Amount } \\ \text { Melter Feed } & 6.3-37.0 \mathrm{mg} / \mathrm{I} \\ \text { Offgas from the OGCT } & 19-249 \mathrm{ppb} \\ \text { Offgas from the ME } & 3.6-154 \mathrm{ppb} \\ \text { Offgas from HEME } & 1.9-34 \mathrm{ppb} \\ \text { OGCT liquid } & 1.9-11.9 \mathrm{mg} / \mathrm{I}\end{array}$


Calculations of the steam stripping efficiency for the demonstrations were also completed. This was defined by the following equation:

(250 lb steam/lb Hg stripped)

: Eff. = (total lb steam/total lb Hg stripped) $\times 100$

where the numerator is the theoretical steam required based on the vapor pressure of mercury at $100^{\circ} \mathrm{C} .2$ Results from the three mercury

designated runs indicated that the amount of steam required per pound of mercury stripped were higher than predicted. The calculated

efficiencies for the overall feeding process were very low because of the low efficiencies experienced during the PHA cycle. The overall efficiencies were 18\% for HGI, $7 \%$ for HG2, and $21 \%$ for HG3. For the other runs, steam efficiencies were good, exceeding the 33\% design basis. 1

For HM4, the efficiency peaked at about $40 \%$ and declined to 25-30\%, which is below the design basis of 33\%. The efficiency for PX3 and PX4 sharply increased with the addition of $\mathrm{PHA}$, and later declined. The peak efficiency was very great and only declined to the design point of $33 \%$ by the end of SME operation. 1

A design final concentration of mercury in the sludge was determined to be 0.45 wto based on available data. ${ }^{2}$ For the three mercury designated runs, this design concentration was exceeded. The results were 0.24 wt\% for HG1, 0.11 wt: for HG2, and 0.08 wto for HG3.2 Exceeding this endpoint is usually considered inefficient processing. For the other runs, the design basis mercury endpoint was attained without increasing the SRAT cycle time. More than $80 \%$ of the initial mercury was removed from the feed in each of the runs. 1

For the HM4 run, the mercury concentration stayed constant until the start of the PHA addition, then it started to decline sharply until approximately $75 \%$ had been removed. No steam stripping was evident during the SME cycle. After completion of the SRAT processing, the mercury concentration was 0.59 wt:. For PX3 and PX4, mercury content decreased throughout the $\mathrm{PHA}$ addition/concentration cycle. At the end of processing, approximately $82 \%$ had been removed in $\mathrm{PX} 3,70-80 \%$ had been removed in PX4, and $90 \%$ had been removed in PX5. The mercury concentration was 0.54 wt\% for PX3, 0.49 wt\% for PX4, and 0.03 wt for PX5. Additional steam stripping occurred in the SME cycle for both PX3 and PX4. The increased removal in PX5 was most likely due to the result of maintaining a vigorous boil with high steam flows during the PHA addition.1

The DF for the melter was considered unity since mercury is not vitrified into the glass.

\section{GLASS PRODUCT QUALITY}

Glass samples were taken at the beginning, middle, and end of each run of the campaign. The durability of the glasses from each run was determined using the Product Consistency Test (PCT). 6 The PCT is a 7day glass leach test that is performed at $90^{\circ} \mathrm{C}$. The test is performed 
on 100-200 mesh glass specimens using ASTM Type I Water as the leach solution.

PCT results for durability indicated that the glasses were more durable than the DWPF Environmental Assessment (EA) glass ${ }^{7}$. A decrease in durability was noticed for the glasses produced after the addition of $\mathrm{NaOH}$ as a trim chemical in HG2, but this was not a direct result of mercury additions. 8 The measured durabilities were comparable to previously produced glasses without mercury additions.

\section{CONCLUSIONS}

A brief summary of the relevant findings of the SRTC campaigns discussed in this paper follows:

- Mercury was successfully removed from the feed to the melter during the steam stripping process in the SRAT/SME.

- In order for mercury washing to be successful, an eveñly distributed vigorous air sparge should be used in the MWWT because of the heavy organics and solids also present.

- Removal of the sample trap and flow measurement device from the transfer line of the SRAT condenser to the MWWT was necessary to avoid accumulation of mercury in the line. Adding slope to the line also helped with this problem.

- Melt rates and melter operating conditions were not impacted by the addition of mercury into the feed stream.

- It did not appear that any mercury exited in the melter offgas line, due to the absence of $\mathrm{Hg}_{2} \mathrm{Cl}_{2}$ in the line.

- Mercury balances were successfully performed around the SRAT and melter offgas system.

- Mercury DE's for the OGCT and HEME were larger than predicted, while they were smaller than predicted for the SAS/Offgas Condenser/Mist Eliminator.

- Calculated steam stripping efficiencies for the mercury designated runs were lower than expected (18\% for HG1, 7\% for HG2, and 21\% for HG3), but exceeded the design basis (33\%) for the other four runs.

- The design final concentration of mercury in the feed $(0.45$ wt: was exceeded for HG1 (0.24 wt:), HG2 (0.11. wt\%), HG3 $(0.08 \mathrm{wt} \%)$, and PX5 (0.03 wt\%). The value for PX5 was far below the design basis and was most likely the result of an increased steam flow, an increased flux, and continuous addition of $\mathrm{PHA}$, since increased SRAT cycle times were not required. 
September 30, $1995 \quad 12$ WSRC-TR-95-0404, Rev.0

- Durability of glasses as measured by the PCT was not affected by the addition of mercury. All glasses performed better than the EA glass.

\section{ACKNOWLEDGEMENTS}

Funding for the summation part of this research and development work was provided by the Department of Energy - Office of Technology Development under the auspices of the Mixed Waste Focus Area and Technical Task Plan SR1-3-20-04. Funding for the studies at the SRTC was provided by the Department of Energy under contract DE-AC09-89SR18035.

\section{REFERENCES}

1. N.D. Hutson, "An Evaluation of Mercury Removal in the IDMS Using the Nitric Acid Flowsheet", WSRC-TR-92-0492, Westinghouse Savannah River Company (October 22, 1992).

2. N.D. Hutson, J.R. Zamecnik, D.H. Miller, M.E. Smith, and J.A. Ritter, "Integrated DWPF Melter System (IDMS) Campaign Report- Mercury Operation", WSRC-TR-91-0363, Westinghouse Savannah River Company, Aiken, SC (May 22, 1991).

3. J.R. Zamecnik, "Measurement of Cesium and Mercury Emissions from the Vitrification of Simulated High Level Radioactive Waste", WWSRC-MS-92-268, Westinghouse Savannah River Company (1992).

4. A.B. Osteen and J.P. Bibler, "Treatment of Radioactive Laboratory Waste for Mercury Removal", Water, Air, and Soil Pollution, Volume 57, Kluwer Academic Publishers (Netherlands), pp. 63-74 (1991).

5. J.A. Ritter, "Mercury Levels in IDMS Condensate", SRTC-LSE-930022, Westinghouse Savannah River Company, Aiken, SC (April 21, 1993).

6. C.M. Jantzen, N.E. Bibler, D.C. Beam, W.G. Ramsey, and B.J. Waters, "Nuclear Waste Product Consistency Test (PCT) - Version 5.0" WWSRC-TR-90-539, Rev. 2, Westinghouse Savannah River Company, Aiken, SC (January 1992).

7. C.M. Jantzen, N.E. Bibler, D.C. Beam, C.I. Crawford, and M.A. Pickett, "Characterization of the Defense Waste Processing Facility (DWPF) Environmental Assessment (EA) Glass standard Reference Material", WSRC-TR-92-346, Westinghouse Savannah River Company, Aiken, SC (June 1, 1993).

8. C.M. Jantzen, "Durability of Glasses from the Hg-Doped Integrated DWFP Melter system (IDMS) Campaign", WSRC-RP-91-371, Westinghouse Savannah River Company, Aiken, SC (August 30; 1992) 